BMJ Open Diabetes

Research \& Care

\title{
Incidence and outcomes of hospitalization for community-acquired, ventilator-associated and non-ventilator hospital-acquired pneumonias in patients with type 2 diabetes mellitus in Spain
}

\author{
Ana Lopez-de-Andres, ${ }^{1}$ Romana Albaladejo-Vicente (D) , ${ }^{2}$ Javier de Miguel-Diez, ${ }^{3}$ \\ Valentin Hernandez-Barrera, ${ }^{1}$ Zichen Ji (D) , ${ }^{3}$ Jose J Zamorano-Leon, ${ }^{4}$ \\ Marta Lopez-Herranz, ${ }^{4}$ Rodrigo Jimenez-Garcia ${ }^{1}$
}

To cite: Lopez-de-Andres A, Albaladejo-Vicente R, de Miguel-Diez J, et al. Incidence and outcomes of hospitalization for communityacquired, ventilator-associated and non-ventilator hospitalacquired pneumonias in patients with type 2 diabetes mellitus in Spain. BMJ Open Diab Res Care 2020;8:e001447. doi:10.1136/ bmjdrc-2020-001447

- Additional material is published online only. To view please visit the journal online (http://dx.doi.org/10.1136/ bmjdrc-2020-001447).

Received 7 April 2020 Revised 13 May 2020 Accepted 21 May 2020

Check for updates

(c) Author(s) (or their employer(s)) 2020. Re-use permitted under CC BY-NC. No commercial re-use. See rights and permissions. Published by BMJ.

For numbered affiliations see end of article.

Correspondence to Professor Romana AlbaladejoVicente;

ralbadal.ucm@gmail.com

\section{ABSTRACT}

Introduction To describe the incidence and compare in-hospital outcomes of community-acquired pneumonia (CAP), ventilator-associated pneumonia (VAP) and nonventilator hospital-acquired pneumonia (NV-HAP) among patients with or without type 2 diabetes mellitus (T2DM) using propensity score matching.

Research design and methods This was a retrospective observational epidemiological study using the 2016-2017 Spanish Hospital Discharge Records.

Results Of 245221 admissions, CAP was identified in 227524 (27.67\% with T2DM), VAP was identified in 2752 (18.31\% with T2DM) and NV-HAP was identified in 14945 (25.75\% with T2DM). The incidence of pneumonia was higher among patients with T2DM (CAP: incidence rate ratio (IRR) $1.44,95 \% \mathrm{Cl} 1.42$ to 1.45 ; VAP: IRR $1.24,95 \% \mathrm{C}$ 1.12 to 1.37 and NV-HAP: IRR $1.38,95 \% \mathrm{Cl} 1.33$ to 1.44 ). In-hospital mortality (IHM) for CAP was $12.74 \%$ in patients with T2DM and $14.16 \%$ in matched controls $(p<0.001)$; in patients with VAP and NV-HAP, IHM was not significantly different between those with and without T2DM (43.65\% vs $41.87 \%, p=0.567$, and $29.02 \%$ vs $29.75 \%, p=0.484$, respectively). Among patients with T2DM, older age and dialysis were factors associated with IHM for all types of pneumonia. In patients with VAP, the risk of IHM was higher in females (OR 1.95, 95\% $\mathrm{Cl} 1.28$ to 2.96).

Conclusion The incidence rates of all types of pneumonia were higher in patients with T2DM. Higher mortality rates in patients with T2DM with any type of pneumonia were associated with older age, comorbidities and dialysis.

\section{INTRODUCTION}

Pneumonia is a major global health problem and a significant cause of morbidity and mortality worldwide. ${ }^{1}$ Several studies have found that the incidence of communityacquired pneumonia (CAP) is increasing and is highly influenced by age and comorbidities. $^{2-4}$ Quan et al in Oxfordshire, UK, found that from 2009 to 2014, the number of hospital admissions of patients with CAP

\section{Significance of this study}

What is already known about this subject?

- Comorbid illnesses, such as type 2 diabetes mellitus (T2DM), are risk factors for any type of pneumonia.

What are the new findings?

- Incidence of all the types of pneumonia analyzed was significantly higher in patients with T2DM than in patients with non-T2DM.

- In-hospital mortality was significantly lower among patients with T2DM and ventilator-associated pneumonia than matched patients with non-diabetes.

- Higher mortality rates in patients with diabetes with any pneumonia type were associated with increasing age, presence of comorbidity and dialysis.

How might these results change the focus of research or clinical practice?

- Our data suggest that future investigations are necessary to identify preventive programs, protocols and interventions than help to prevent and mitigate this burdensome complication.

increased by $\approx 9 \%$ per year. ${ }^{5}$ Among infections acquired during hospitalization, hospitalacquired pneumonia (HAP) is the most frequent, accounting for an estimated $16.6 \%$ of all hospital infections. ${ }^{6}$

The investigations over the last years have been mainly centered on ventilator-associated pneumonia (VAP), and this has resulted in improved methods for prevention and management, which has reduced the incidence, mortality and morbidity caused by this infection. ${ }^{78}$ However, some hospitalized patients develop non-ventilator hospitalacquired pneumonia (NV-HAP). Giuliano et $a l$ analyzed the US National Inpatient Sample dataset and described that NV-HAP causes an 
increase in the costs, length of hospital stays and mortality of hospitalized patients. ${ }^{9}$

It has been reported that comorbid illnesses, such as type 2 diabetes mellitus (T2DM), are risk factors for any type of pneumonia. ${ }^{10}$ The specific role of T2DM has been previously identified. ${ }^{11-13}$ Recently, Campling et al found that patients with T2DM have a significantly higher risk of hospital admission for CAP (OR 1.18; 95\% CI 1.13 to 1.23$).{ }^{13}$ Reasons for the higher risk among patients with diabetes include impaired immunity as a result of hyperglycemia, altered lung function and greater risk of aspiration. ${ }^{14}$ However, the results are not conclusive, and Vardakas et al reported that for HAP, diabetes is not a risk factor. ${ }^{15}$

Diabetes is a major public health problem in Spain. According to the Base de Datos Clínicos de Atención Primaria/Primary Care Clinical Database (BDCAP) that covers 4.7 million patients attended at Spanish primary care centers, the overall prevalence of diabetes in year 2016 was of $6.7 \%$ (7.3\% for men and $6.1 \%$ for women). The results of the Spanish National Health Survey conducted in year 2017 (SNHS2017) showed a self-reported prevalence of $7.8 \%$ for those aged 15 years or over. Finally, the Di@bet.es Study, a national study in Spain including 5072 individuals aged $\geq 18$ years, found that the overall prevalence of diabetes mellitus adjusted for age and sex was $13.8 \%$ (95\% CI $12.8 \%$ to $14.7 \%$ ), of which $6.0 \%$ had unknown diabetes $(95 \%$ CI $5.4 \%$ to $6.7 \%){ }^{16-18}$

Given this background of contrasting findings, in this study, we aim to (1) examine the incidence, characteristics and outcomes of CAP, VAP and NV-HAP among patients with or without T2DM in Spain in 2016-2017; (2) compare in-hospital outcomes of CAP, VAP and NV-HAP between patients with and without T2DM and (3) identify factors associated with in-hospital mortality (IHM) after CAP, VAP and NV-HAP among patients with T2DM.

\section{RESEARCH DESIGN AND METHODS}

Design, setting and participants

This observational retrospective epidemiological study was conducted using the Hospital Discharge Records of the Spanish National Health System (RAE-CMBD, Registro de Actividad de Atención Especializada-Conjunto Minimo Básico de Datos) from January 1, 2016 to December 31, 2017. The RAE-CMBD includes up to 20 discharge diagnoses and procedures performed during the hospital stay. Coding was performed using the International Classification of Disease, 10th Revision (ICD-10) ${ }^{19}$ Each discharge diagnosis has a "Present on Admission (POA)" indicator assigned according to the ICD-10, Clinical Modification (ICD-10-CM) Official Guidelines for Coding and Reporting (https://icdlist.com/icd-10/guidelines/). The reporting options and definitions for POA are "Y" (present at admission); "N" (not present at admission); "U" (lack documentation to determine presence at admission); "W" (provider is unable to clinically determine if the condition was present) and unreported/not used.

The study population comprised all hospital admissions of patients aged 40 years or older who were hospitalized with a pneumonia diagnosis. We defined CAP as any hospitalization that included any of the following conditions: (1) any ICD-10 code from J12 to J18 as primary diagnosis with a POA indicator of " $\mathrm{Y}$ " and (2) any ICD-10 code from J12 to J18 in any of the secondary diagnosis fields (2-20) and with a POA indicator of "Y." VAP is defined as any hospitalization with a diagnosis ICD-10 code J95.851 in any diagnosis position and a POA indicator of "N" (not present at admission). NV-HAP is characterized by pneumonia that was not present when the patient was admitted to the hospital and that was not associated with the use of mechanical ventilation during hospitalization. We identified NV-HAP in those patients with any ICD-10 codes from J12 to J18 in any diagnosis position and with a POA indicator coded as "N" who had a hospitalization $\geq 48$ hours. To avoid the possibility that pneumonia was associated with the use of ventilatory support, patients with codes for non-invasive or invasive mechanical ventilation in any procedure fields were excluded from the NV-HAP group.

For study purposes, we excluded hospitalized patients with influenza-related pneumonia (ICD-10 codes: J09, $\mathrm{J} 10, \mathrm{~J} 11)$, those with aspiration pneumonia (J69, J69.0, J69.1, J69.8) and those with ICD-10 codes from J12 to J18 in any diagnosis fields and with a POA indicator coded as "U," "W" or "unreported/not used."

We grouped admissions by diabetes status as follows: "patients with T2DM" if any E11.x ICD-10 codes were recorded in any diagnosis position (1-20) or "patients without T2DM" if no codes for T2DM appeared in any diagnostic position. We excluded people with type 1 diabetes mellitus (T1DM; ICD-10 codes: E10.x) in any diagnosis position.

\section{Study variables}

Our main study variables are the incidence, IHM and length of hospital stay (LOHS). Covariates include age, sex, comorbidities and therapeutic procedures.

Comorbidity was assessed using the Charlson Comorbidity Index (CCI) ${ }^{20}$ The ICD-10 codes for the CCI conditions in any of the discharge diagnosis are those described by Quan et $a l^{20}$ We provide results for each condition included in the CCI and a sum of the number of these conditions.

The RAE-CMBD includes a variable with the DiagnosisRelated Groups categorized as Medical/Surgical/Other that was used to identify patients who underwent any type of surgical procedure during their hospital admission. ${ }^{19}$

We specifically identified the following procedures: axial CT of the thorax, bronchial fibroscopy, non-invasive mechanical ventilation, invasive mechanical ventilation and dialysis. Additionally, a diagnosis of pressure ulcer was identified in any diagnosis field. The ICD-10 codes 
used for this purpose are shown in online supplementary table 1.

The pathogens codified in any diagnosis field among patients with pneumonia were identified with the ICD-10 codes: A48.1 for Legionella; B37.1 for candidiasis; B44.9 for Aspergillus; J13 for Streptococcus pneumoniae; J14 for Haemophilus influenzae, $\mathrm{J} 15$ for Klebsiella pneumoniae, J15.1 for Pseudomonas aeruginosa; J15.211 and J15.212 for Staphylococcus aureus; J15.4 for non-specified Streptococcus; J15.5 for Escherichia coli and J15.6 for other Gram-negative bacteria. Regarding pathogen detections, according to the RAE-CMBD methodology, only pathogens that are laboratory confirmed can be codified. ${ }^{19}$

\section{Propensity score matching (PSM) method}

We used propensity scores (PSs) to obtain unbiased matched populations of patients with and without T2DM. ${ }^{21}$ The PSM method consists of selecting patients with T2DM and non-T2DM with the same or similar PS obtained with multivariable logistic regression so we match the distribution of confounding factors for both populations. ${ }^{2223}$ The variables included in the PSM model were sex, age, CCI and whether a surgery was performed.

\section{Statistical methods}

The incidence rates of hospital admissions for the three types of pneumonia according to the presence of T2DM were calculated per 100000 individuals. We used data from the 2016/2017 Spanish National Health Survey and Spanish National Institute of Statistics to estimate the number of people with T2DM in Spain by sex and age group. ${ }^{1724}$

Categorical variables are shown as proportions, and continuous variables are shown as the means with SD. To compare patients with and without T2DM, the statistical tests conducted for continuous variables were the t-test (age) or Mann-Whitney test (LOHS); for categorical variables, we used the $\chi^{2}$ test. To assess differences in the incidence rates between patients with and without T2DM, we used age-adjusted and sex-adjusted Poisson regression.

McNemar's test and paired t-test were used to compare study groups after PSM. ${ }^{25}$

Multivariable logistic regression analyses were constructed to identify predictors of IHM among patients with T2DM.

To conduct the multivariable regression models (logistic and Poisson), the following steps were done: (1) Bivariate analysis of each variable. (2) Selection of variables to be included in the multivariable analysis. We included all variables with a significant association $(\mathrm{p}<0.10)$ in the bivariate test and those identified as important in the literature search. (3) The importance of each variable included in the model was verified using the Wald statistic and successive models were compared with the previous using the Likelihood Ratio (LR) test. (4) Once the model was obtained, we analyzed possible linearity between variables and checked for interactions.
The results of multivariable models are shown as incidence rate ratios (IRRs) with 95\% CIs for Poisson regression and as ORs with their $95 \%$ CIs for logistic regression.

Stata V.14 (Stata, College Station, Texas, USA) was used for data analysis.

\section{Ethical aspects}

According to the Spanish legislation, as we used the RAE-CMBD, a de-identified retrospective public access database that is provided freely to all investigators by the Spanish Ministry of Health, it was not necessary to obtain approval from an ethics committee.

\section{RESULTS}

Incidence of CAP, VAP and NV-HAP according to T2DM status

We analyzed 245221 hospitalized patients aged $\geq 40$ years with pneumonia in Spain (2016-2017). CAP diagnosis was identified in 227524 patients $(27.67 \%$ with T2DM), VAP diagnosis was identified in $2752(18.31 \%$ with T2DM) and 14945 patients were identified as having an NV-HAP diagnosis $(25.75 \%$ with T2DM).

The crude incidence of CAP was significantly higher in people with T2DM than in non-diabetic people (2057.58 cases per $100000 \mathrm{~T} 2 \mathrm{DM}$ population vs 726.82 cases per 100000 non-T2DM population; $\mathrm{p}<0.001)$. Crude incidences of VAP and NV-HAP coding were not significantly higher in patients with T2DM than in patients without T2DM (table 1). However, after age-adjusted and sexadjusted Poisson regression, we found that the incidence of all the types of pneumonia analyzed was higher among patients with T2DM than among those without (CAP: IRR 1.44, 95\% CI 1.42 to 1.45; VAP: IRR 1.24, 95\% CI 1.12 to 1.37 and NV-HAP: IRR $1.38,95 \%$ CI 1.33 to 1.44 ).

\section{Clinical characteristics and in-hospital outcomes of patients} hospitalized with CAP, VAP and NV-HAP according to T2DM status

In both groups studied, men represented a higher proportion of patients with CAP than women $(61.95 \%$ and $58.72 \%$ for patients with and without T2DM, respectively, $\mathrm{p}<0.001)$. Overall, the mean age was significantly higher among patients with T2DM (78.09; $\mathrm{SD}=10.4$ years) than non-T2DM (75.47; $\mathrm{SD}=14$ years), and patients with T2DM also had a higher mean CCI $(\mathrm{p}<0.001)$. Specifically, there was a higher prevalence of congestive heart failure $(28.57 \%$ vs $19.99 \%)$, peripheral vascular disease $(7.53 \%$ vs $4.61 \%)$, cerebrovascular disease $(8.7 \%$ vs $5.91 \%$ ), dementia $(9.96 \%$ vs $9.34 \%)$, chronic obstructive pulmonary disease (COPD) $(34.08 \%$ vs $32.77 \%)$, renal disease (26.9\% vs $15.24 \%$ ), and moderate/severe liver disease $(1.09 \%$ vs $0.97 \%)$, and the prevalence of myocardial infarction was two times higher (all $\mathrm{p}$ values $<0.001)$. During hospitalization, patients with diabetes underwent surgery $(3.01 \%)$ significantly less often than patients with non-diabetes $(3.34 \%)$. The mean LOHS was approximately 9.7 days in patients with both T2DM and non-T2DM. The crude IHM was $12.74 \%$ for patients 


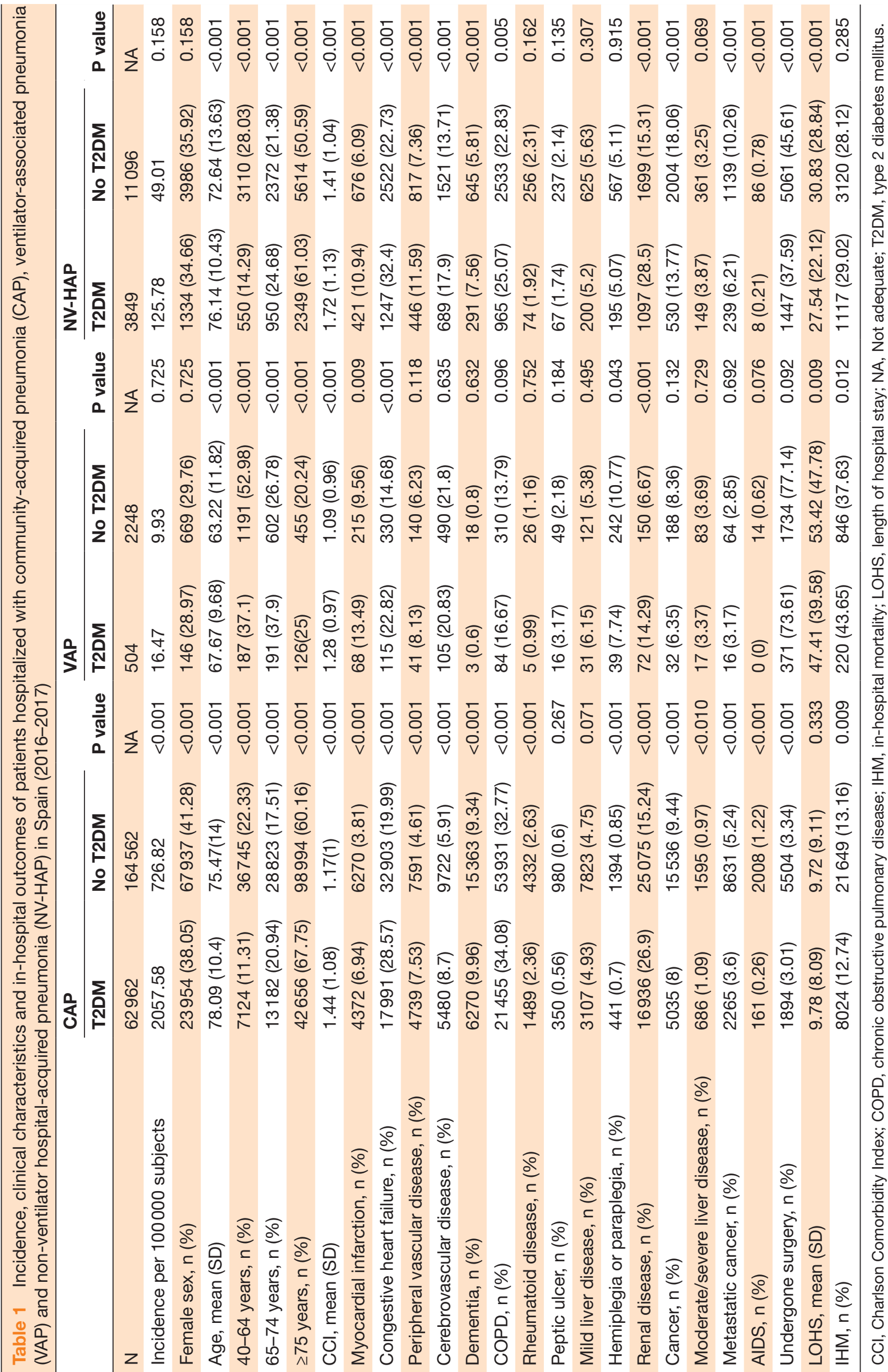


with T2DM and $13.16 \%$ for people with non-diabetes $(\mathrm{p}=0.009)$ (table 1$)$.

In patients with VAP, there was a significant male predominance $(71.03 \%$ and $70.24 \%$ for T2DM and nonT2DM, respectively). Overall, patients with T2DM were significantly older than those without diabetes $(67.67$ vs 63.22 years; $\mathrm{p}<0.001)$ and had a higher mean CCI $(1.28 \pm 0.97$ for T2DM vs $1.09 \pm 0.96$ non-T2DM; $\mathrm{p}<0.001)$. Specifically, patients with T2DM had a higher prevalence of myocardial infarction $(13.49 \%$ vs $9.56 \% ; \mathrm{p}=0.009)$, congestive heart failure $(22.82 \%$ vs $14.68 \%$; $\mathrm{p}<0.001)$ and renal disease $(14.29 \%$ vs $6.67 \%$; $\mathrm{p}<0.001)$. The overall mean LOHS was significantly lower in patients with T2DM (47.41 vs 53.42 days; $\mathrm{p}=0.009$ ). Crude IHM was $43.65 \%$ for patients with T2DM and $37.63 \%$ for patients with non-T2DM $(\mathrm{p}=0.012)$ (table 1$)$.

As described in the other two types of pneumonia studied, NV-HAP was more common among men in addition to patients with diabetes $(65.34 \%$ and $64.08 \%$ for patients with T2DM and non-diabetes, respectively). The mean age was higher among patients with T2DM (76.14 vs 72.64 years; $p<0.001)$, and they also had a higher mean CCI (1.72 vs $1.41 ; p<0.001)$. Specifically, there was a higher prevalence of myocardial infarction $(10.94 \%$ vs $6.09 \%$; $\mathrm{p}<0.001)$, congestive heart failure $(32.4 \%$ vs $22.73 \%$; $\mathrm{p}<0.001)$, peripheral vascular disease $(11.59 \%$ vs $7.36 \%$; $\mathrm{p}<0.001)$, cerebrovascular disease $(17.9 \%$ vs $13.71 \%$; $\mathrm{p}<0.001)$, dementia $(7.56 \%$ vs $5.81 \%$; $<<0.001)$, COPD (25.07\% vs $22.83 \% ; \mathrm{p}=0.005)$ and renal disease $(28.5 \%$ vs $15.31 \% ; \mathrm{p}<0.001)$. Patients with T2DM included in our investigation had undergone surgery significantly less frequently than patients with non-diabetes $(37.59 \%$ vs $45.61 \% ; \mathrm{p}<0.001)$. The mean LOHS was significantly lower in patients with T2DM than in patients with nonT2DM (27.54 vs 30.83 days; $p<0.001)$. The crude IHM was approximately $29 \%$ in both groups (table 1 ).

\section{Distribution of study covariates among patients with and without T2DM hospitalized with CAP, VAP and NV-HAP after PSIM}

Shown in table 2 are the characteristics of patients admitted with CAP and T2DM as well as those of their PSM non-diabetic controls.

Patients with T2DM had significantly higher rates of non-invasive mechanical ventilation and dialysis (2.33\% vs $2.02 \% ; \mathrm{p}<0.001$ and $1.36 \%$ vs $1.17 \%$; $\mathrm{p}=0.002$ ). However, patients with T2DM had lower rates of axial CT of the thorax $(6.12 \%$ vs $6.52 \% ; \mathrm{p}=0.004)$ and bronchial fibroscopy $(0.82 \%$ vs $0.92 \%$; $\mathrm{p}=0.049)$. After PSM, the IHM during admission for CAP was $12.74 \%$ in patients with T2DM and $14.16 \%$ in matched controls $(p<0.001)$ (table 2).

After PSM, the prevalence of S. pneumoniae $(7.19 \%$ vs $7.79 \% ; \mathrm{p}<0.001)$ and that of $P$. aeruginosa $(0.96 \%$ vs $1.12 \%$; $\mathrm{p}=0.004$ ) was lower among patients with T2DM (online supplementary table 2 ).

In patients with VAP (table 3), when we compared patients with T2DM with matched controls after PSM, we found significantly lower rates of axial CT in the people with T2DM $(5.56 \%$ vs $9.52 \%$; $=0.017)$. The mean LOHS was $47.41 \pm 39.58$ days among patients with T2DM and 53.52 \pm 51.18 days among matched controls $(p=0.034) \quad$ (table 3$)$. The IHM was not significantly different between those with and without T2DM $(43.65 \%$ vs $41.87 \%$; $\mathrm{p}=0.567$ ).

The prevalence of $S$. aureus was lower among patients with T2DM than among matched controls $(0.99 \%$ vs 3.37\%; $p=0.010$ ) (online supplementary table 2).

After PSM, when comparing patients with T2DM with matched controls who had an episode of NV-HAP (table 4 ), we found that pressure ulcers $(6.42 \%$ vs $5.04 \%$; $\mathrm{p}=0.009$ ) were more frequently identified among those without T2DM (table 4). No significant differences were found regarding LOHS (27.54 days vs 28.18 days; $\mathrm{p}=0.394)$ or IHM (29.02\% vs $29.75 \%$; $\mathrm{p}=0.484)$.

As shown in online supplementary table 2, the prevalence of $H$. influenzae was lower among patients with T2DM $(0.55 \%$ vs $0.94 \% ; p=0.046)$.

\section{Multivariable logistic regression analysis of the factors associated with IHM among patients with T2DM}

Table 5 shows the results of the multivariable analysis of the factors associated with IHM after CAP, VAP and NV-HAP among patients with T2DM. Older age and dialysis were factors associated with IHM in the three types of pneumonia analyzed.

The presence of congestive heart failure, peripheral vascular disease, cancer, moderate/severe liver disease and metastatic cancer increased the probability of dying in patients with CAP and NV-HAP. The presence of pressure ulcers was associated with IHM in patients with CAP and NV-HAP.

The presence of hemiplegia or paraplegia increased the probability of dying in patients with CAP. COPD was a factor associated with IHM in patients with VAP, whereas it was associated with lower IHM in patients with CAP.

In patients with CAP, the presence of dementia and renal disease increased the probability of dying. Furthermore, patients who underwent mechanical ventilation (non-invasive and invasive) had a higher risk of IHM. However, patients who underwent axial CT of the thorax had a lower risk of dying, and the presence of $S$. pneumoniae and $H$. influenzae were also associated with lower mortality.

In patients with VAP, the risk of IHM was higher in females. In addition, the presence of myocardial infarction was associated with higher IHM.

Previous surgery was a factor associated with lower mortality in patients with VAP and NV-HAP.

\section{DISCUSSION}

This population-based study showed that the incidence of all types of pneumonia analyzed was significantly higher in patients with T2DM than in patients with non-T2DM.

The incidence of CAP observed in our study is consistent with our earlier findings and with the findings of 
Table 2 Distribution of study covariates and hospital outcomes of patients with and without T2DM hospitalized with community-acquired pneumonia in Spain (2016-2017), after propensity score matching

\begin{tabular}{|c|c|c|c|}
\hline & T2DM & No T2DM & $P$ value \\
\hline Male sex, n (\%) & $39008(61.95)$ & $39351(62.5)$ & 0.046 \\
\hline Female sex, n (\%) & 23954 (38.05) & $23611(37.5)$ & \\
\hline Age, mean (SD) & $78.09(10.4)$ & $78.99(11.05)$ & $<0.001$ \\
\hline 40-64 years, $n(\%)$ & $7124(11.31)$ & $7123(11.31)$ & $<0.001$ \\
\hline 65-74 years, n (\%) & $13182(20.94)$ & $11339(18.01)$ & \\
\hline$\geq 75$ years, $n(\%)$ & $42656(67.75)$ & $44500(70.68)$ & \\
\hline $\mathrm{CCl}$, mean (SD) & $1.44(1.08)$ & $1.41(1.07)$ & $<0.001$ \\
\hline Myocardial infarction, n (\%) & $4372(6.94)$ & $4020(6.38)$ & $<0.001$ \\
\hline Congestive heart failure, $\mathrm{n}(\%)$ & $17991(28.57)$ & $17795(28.26)$ & 0.221 \\
\hline Peripheral vascular disease, $\mathrm{n}(\%)$ & $4739(7.53)$ & $4441(7.05)$ & 0.001 \\
\hline Cerebrovascular disease, $\mathrm{n}(\%)$ & $5480(8.7)$ & $5191(8.24)$ & 0.003 \\
\hline Dementia, n (\%) & $6270(9.96)$ & $6586(10.46)$ & 0.003 \\
\hline COPD, n (\%) & $21455(34.08)$ & $21765(34.57)$ & 0.066 \\
\hline Rheumatoid disease, $\mathrm{n}(\%)$ & $1489(2.36)$ & $1312(2.08)$ & 0.001 \\
\hline Peptic ulcer, n (\%) & $350(0.56)$ & $252(0.4)$ & $<0.001$ \\
\hline Mild liver disease, n (\%) & $3107(4.93)$ & $2891(4.59)$ & 0.004 \\
\hline Hemiplegia or paraplegia, $n(\%)$ & $441(0.7)$ & $348(0.55)$ & 0.001 \\
\hline Renal disease, $n(\%)$ & $16936(26.9)$ & $16450(26.13)$ & 0.002 \\
\hline Cancer, n (\%) & $5035(8)$ & $4855(7.71)$ & 0.059 \\
\hline Moderate/severe liver disease, $n(\%)$ & $686(1.09)$ & $594(0.94)$ & 0.010 \\
\hline Metastatic cancer, n (\%) & $2265(3.6)$ & 2007 (3.19) & $<0.001$ \\
\hline AIDS, n (\%) & $161(0.26)$ & $140(0.22)$ & 0.226 \\
\hline Undergone surgery, n (\%) & $1894(3.01)$ & $1689(2.68)$ & 0.001 \\
\hline Axial CT of thorax, $n(\%)$ & $3856(6.12)$ & 4108 (6.52) & 0.004 \\
\hline Bronchial fibroscopy, n (\%) & $515(0.82)$ & $580(0.92)$ & 0.049 \\
\hline Non-invasive mechanical ventilation, $\mathrm{n}(\%)$ & $1466(2.33)$ & $1270(2.02)$ & $<0.001$ \\
\hline Invasive mechanical ventilation, $\mathrm{n}(\%)$ & $1285(2.04)$ & $1309(2.08)$ & 0.634 \\
\hline Dialysis, $\mathrm{n}(\%)$ & $857(1.36)$ & $737(1.17)$ & 0.002 \\
\hline Pressure ulcer, n (\%) & $1805(2.87)$ & $1692(2.69)$ & 0.053 \\
\hline LOHS, mean (SD & 9.78 (8.09) & 9.77 (8.39) & 0.956 \\
\hline IHM, n (\%) & 8024 (12.74) & 8917 (14.16) & $<0.001$ \\
\hline
\end{tabular}

$\mathrm{CCl}$, Charlson Comorbidity Index; COPD, chronic obstructive pulmonary disease; IHM, in-hospital mortality; LOHS, length of hospital stay; T2DM, type 2 diabetes mellitus.

other authors. ${ }^{26}{ }^{27}$ In the USA, among 46237 subjects aged $>65$ years, it was found that patients with diabetes had a 1.52 (95\% CI 1.29 to 1.78$)$ higher risk of CAP than those without this disease. ${ }^{28}$ In Canada, the IRR for pneumonia was 1.46 times higher (95\% CI 1.42 to 1.49 ) for patients with diabetes. ${ }^{12}$ In Denmark, a study found that T2DM increased the risk of pneumonia-related hospitalization 1.2-fold. ${ }^{11}$ They concluded that a longer duration of diabetes and poor glycemic control increase the risk of CAP-related hospitalization. ${ }^{11}$

The higher incidence of VAP and NV-HAP in patients with T2DM is consistent with previous Spanish reports. ${ }^{29} 30$ Karatas et al reported a 1.2-fold increased risk of VAP among diabetes sufferers. ${ }^{31}$ A longer duration of the disease and poor glycemic control have been associated with a greater risk of VAP, as described for CAP. ${ }^{32}$

Surgery is a well-established risk factor for pneumonia. ${ }^{33} 34$ A population-based study in Spain reported that patients with T2DM had a 1.21-fold higher risk (IRR, $1.2195 \%$ CI 1.03 to 1.42 ) of suffering from postoperative pneumonia than those without diabetes and concluded that increased risk in patients with T2DM might be related to longer length of stay and higher rates of readmission. ${ }^{29}$

The use of non-invasive mechanical ventilation was higher in patients with diabetes admitted with CAP than in non-diabetic controls. In a study about mechanical 
Table 3 Distribution of study covariates and hospital outcomes of patients with and without T2DM hospitalized with ventilator-associated pneumonia in Spain (2016-2017), after propensity score matching

\begin{tabular}{|c|c|c|c|}
\hline & T2DM & No T2DM & $P$ value \\
\hline Male sex, $\mathrm{n}(\%)$ & $358(71.03)$ & $359(71.23)$ & 0.945 \\
\hline Female sex, n (\%) & $146(28.97)$ & $145(28.77)$ & \\
\hline Age, mean (SD) & $67.67(9.68)$ & $68.25(10.48)$ & 0.367 \\
\hline 40-64 years, $\mathrm{n}(\%)$ & $187(37.1)$ & $167(33.13)$ & 0.178 \\
\hline $65-74$ years, $n(\%)$ & $191(37.9)$ & $186(36.9)$ & \\
\hline$\geq 75$ years, $n(\%)$ & $126(25)$ & $151(29.96)$ & \\
\hline $\mathrm{CCl}$, mean (SD) & $1.28(0.97)$ & $1.22(1)$ & 0.370 \\
\hline Myocardial infarction, $\mathrm{n}(\%)$ & 68 (13.49) & 69 (13.69) & 0.927 \\
\hline Congestive heart failure, $\mathrm{n}(\%)$ & $115(22.82)$ & $111(22.02)$ & 0.763 \\
\hline Peripheral vascular disease, $n(\%)$ & $41(8.13)$ & $37(7.34)$ & 0.637 \\
\hline Cerebrovascular disease, $\mathrm{n}(\%)$ & $105(20.83)$ & $88(17.46)$ & 0.174 \\
\hline Dementia, n (\%) & $3(0.6)$ & $4(0.79)$ & 0.704 \\
\hline COPD, n (\%) & $84(16.67)$ & $78(15.48)$ & 0.607 \\
\hline Rheumatoid disease, $n(\%)$ & $5(0.99)$ & $3(0.6)$ & 0.478 \\
\hline Peptic ulcer, n (\%) & $16(3.17)$ & $13(2.58)$ & 0.572 \\
\hline Mild liver disease, $n(\%)$ & $31(6.15)$ & $40(7.94)$ & 0.268 \\
\hline Hemiplegia or paraplegia, $\mathrm{n}(\%)$ & $39(7.74)$ & $37(7.34)$ & 0.811 \\
\hline Renal disease, $n(\%)$ & $72(14.29)$ & $64(12.7)$ & 0.461 \\
\hline Cancer, n (\%) & $32(6.35)$ & $40(7.94)$ & 0.328 \\
\hline Moderate/severe liver disease, $\mathrm{n}(\%)$ & $17(3.37)$ & $15(2.98)$ & 0.719 \\
\hline Metastatic cancer, n (\%) & $16(3.17)$ & $17(3.37)$ & 0.860 \\
\hline AIDS, n (\%) & $0(0)$ & $0(0)$ & NA \\
\hline Undergone surgery, n (\%) & $371(73.61)$ & $381(75.6)$ & 0.469 \\
\hline Axial CT of thorax, $\mathrm{n}(\%)$ & $28(5.56)$ & $48(9.52)$ & 0.017 \\
\hline Bronchial fibroscopy, n (\%) & $28(5.56)$ & $29(5.75)$ & 0.892 \\
\hline Dialysis, $\mathrm{n}(\%)$ & $86(17.06)$ & $76(15.08)$ & 0.391 \\
\hline Pressure ulcer, n (\%) & $54(10.71)$ & 50 (9.92) & 0.679 \\
\hline LOHS, mean (SD) & $47.41(39.58)$ & $53.52(51.18)$ & 0.034 \\
\hline $\mathrm{IHM}, \mathrm{n}(\%)$ & $220(43.65)$ & $211(41.87)$ & 0.567 \\
\hline
\end{tabular}

$\mathrm{CCl}$, Charlson Comorbidity Index; COPD, chronic obstructive pulmonary disease; IHM, in-hospital mortality; LOHS, length of hospital stay; NA, Not adequate; T2DM, type 2 diabetes mellitus.

ventilation use in 56158 patients with CAP who received ventilator support, the authors found an increase in the prevalence of comorbidities over time that could partially explain the higher need for ventilatory support. ${ }^{35}$

We agree with other authors who found that mechanical ventilation was a strong risk factor for IHM in patients with diabetes with CAP and NV-HAP. ${ }^{26} 29$

Our study supports that patients with T2DM and CAP had significantly higher rates of dialysis use than control patients, and dialysis was a risk factor associated with IHM for the three types of pneumonia analyzed. Similar results have been reported previously, suggesting that altered immune function and greater healthcare contact make dialysis patients an especially susceptible risk group for any type of pneumonia. ${ }^{36} 37$
Regarding the pathogens isolated, S. pneumoniae was the most frequent infectious agent among patients with T2DM with CAP. It has been suggested that the increase in coverage of pneumococcal vaccination may in part reduce the role of this pathogen over time. ${ }^{38}$ In Spain, this vaccine is recommended and provided free of charge for T2DM sufferers and all subjects aged 65 years or older. $^{39}$

Among patients with diabetes suffering VAP and NV-HAP, the most frequently isolated pathogens were Gram-negative bacteria, among which Pseudomonas was found in $3.97 \%$ of patients with VAP and $2.86 \%$ of patients with NV-HAP. Similar findings were reported by other authors. ${ }^{40} 41$ 
Table 4 Distribution of study covariates and hospital outcomes of patients with and without T2DM hospitalized with nonventilator hospital-acquired pneumonia in Spain (2016-2017), after propensity score matching

\begin{tabular}{|c|c|c|c|}
\hline & T2DM & No T2DM & $P$ value \\
\hline Male sex, $n(\%)$ & $2515(65.34)$ & $2485(64.56)$ & 0.474 \\
\hline Female sex, n (\%) & $1334(34.66)$ & $1364(35.44)$ & \\
\hline Age, mean (SD) & $76.14(10.43)$ & $76.8(12.05)$ & 0.010 \\
\hline 40-64 years, $n(\%)$ & $550(14.29)$ & $637(16.55)$ & $<0.001$ \\
\hline $65-74$ years, $n(\%)$ & $950(24.68)$ & $751(19.51)$ & \\
\hline$\geq 75$ years, $n(\%)$ & $2349(61.03)$ & $2461(63.94)$ & \\
\hline $\mathrm{CCl}$, mean (SD) & $1.72(1.13)$ & $1.67(1.15)$ & 0.036 \\
\hline Myocardial infarction, $\mathrm{n}(\%)$ & $421(10.94)$ & $402(10.44)$ & 0.483 \\
\hline Congestive heart failure, $\mathrm{n}(\%)$ & $1247(32.4)$ & $1224(31.8)$ & 0.574 \\
\hline Peripheral vascular disease, $\mathrm{n}(\%)$ & 446 (11.59) & $420(10.91)$ & 0.348 \\
\hline Cerebrovascular disease, $\mathrm{n}(\%)$ & $689(17.9)$ & $681(17.69)$ & 0.812 \\
\hline Dementia, n (\%) & $291(7.56)$ & $297(7.72)$ & 0.797 \\
\hline COPD, n (\%) & $965(25.07)$ & $964(25.05)$ & 0.979 \\
\hline Rheumatoid disease, $\mathrm{n}(\%)$ & $74(1.92)$ & $65(1.69)$ & 0.441 \\
\hline Peptic ulcer, n (\%) & $67(1.74)$ & $74(1.92)$ & 0.552 \\
\hline Mild liver disease, $\mathrm{n}(\%)$ & $200(5.2)$ & $186(4.83)$ & 0.465 \\
\hline Hemiplegia or paraplegia, $\mathrm{n}(\%)$ & $195(5.07)$ & $169(4.39)$ & 0.163 \\
\hline Renal disease, $\mathrm{n}(\%)$ & $1097(28.5)$ & $1050(27.28)$ & 0.232 \\
\hline Cancer, n (\%) & $530(13.77)$ & $516(13.41)$ & 0.641 \\
\hline Moderate/severe liver disease, $n(\%)$ & $149(3.87)$ & $156(4.05)$ & 0.683 \\
\hline Metastatic cancer, n (\%) & $239(6.21)$ & $200(5.2)$ & 0.055 \\
\hline AIDS, $n(\%)$ & $8(0.21)$ & $5(0.13)$ & 0.405 \\
\hline Undergone surgery, $\mathrm{n}(\%)$ & $1447(37.59)$ & $1461(37.96)$ & 0.742 \\
\hline Axial CT of thorax, $n(\%)$ & $313(8.13)$ & $313(8.13)$ & 1.000 \\
\hline Bronchial fibroscopy, n (\%) & 49 (1.27) & $40(1.04)$ & 0.370 \\
\hline Dialysis, n (\%) & $214(5.56)$ & $199(5.17)$ & 0.448 \\
\hline Pressure ulcer, n (\%) & $247(6.42)$ & $194(5.04)$ & 0.009 \\
\hline LOHS, mean (SD) & $27.54(22.12)$ & $28.18(23.79)$ & 0.394 \\
\hline IHM, n (\%) & 1117 (29.02) & 1145 (29.75) & 0.484 \\
\hline
\end{tabular}

$\mathrm{CCl}$, Charlson Comorbidity Index; COPD, chronic obstructive pulmonary disease; IHM, in-hospital mortality; LOHS, length of hospital stay; T2DM, type 2 diabetes mellitus.

The mortality associated with pneumonia seems to be decreasing over time in Spain. ${ }^{42}$ Our study highlights key differences in IHM. The mortality rate in patients with T2DM with CAP was lower than that in matched controls, and no significant differences were found regarding VAP and NV-HAP in patients with T2DM. These results add important evidence to previous information which indicated that the presence of T2DM was not a risk factor for death during admission for $\mathrm{CAP}^{43}$ Several studies have suggested that hyperglycemia or comorbid conditions and not diabetes itself are responsible for higher IHM after CAP and HAP. ${ }^{44}$ Another suggested explanation for the lower mortality among patients with diabetes after CAP is the obesity paradox. ${ }^{2645}$ Furthermore, in our opinion, it is possible that patients with CAP and T2DM are admitted to the hospital and are not sent home with oral treatment more frequently than patients without diabetes with equal clinical severity. This would result in a selection bias that could partly explain the lower IHM among patients with T2DM.

As we expected, older age and comorbidity were factors associated with IHM for the three types of pneumonia analyzed. Different studies highlighted that elderly individuals frequently suffer comorbid conditions, which is a factor associated with poor prognosis. ${ }^{28}{ }^{46}$ Another predictor of higher postoperative mortality was pressure ulcers in patients with CAP and NV-HAP. In the USA, a study using the National Inpatient Sample database from 2008 to 2012 found that among 670767 patients with pressure ulcers, the pneumonia mortality rate was five times higher (OR 5.08, CI: 5.03 to $5.1 ; \mathrm{p}<0.001$ ) than that in patients without pressure ulcers. ${ }^{47}$ 
Table 5 Multivariable analysis of factors associated with in-hospital mortality during admissions for community-acquired pneumonia (CAP), ventilator-associated pneumonia (VAP) and non-ventilator hospital-acquired pneumonia (NV-HAP) among patients with T2DM

\begin{tabular}{|c|c|c|c|}
\hline & CAP & VAP & NV-HAP \\
\hline & OR $(95 \% \mathrm{Cl})$ & OR $(95 \% \mathrm{Cl})$ & OR $(95 \% \mathrm{Cl})$ \\
\hline Female sex & 1.01 (0.96 to 1.07$)$ & 1.95 (1.28 to 2.96$)$ & $1.04(0.89$ to 1.21$)$ \\
\hline 40-64 years & 1 & 1 & 1 \\
\hline $65-74$ years & $1.5(1.34$ to 1.68$)$ & 1.58 (1.01 to 2.46$)$ & 1.45 (1.12 to 1.87$)$ \\
\hline$\geq 75$ years & 2.91 (2.62 to 3.23 ) & 2.55 (1.54 to 4.21$)$ & 1.96 (1.54 to 2.5$)$ \\
\hline Myocardial infarction & & $1.98(1.14$ to 3.45$)$ & \\
\hline Congestive heart failure & 1.25 (1.19 to 1.32$)$ & & $1.21(1.03$ to 1.41$)$ \\
\hline Peripheral vascular disease & $1.53(1.41$ to 1.65$)$ & & $1.47(1.23$ to 1.77$)$ \\
\hline Dementia & 2.08 (1.94 to 2.23$)$ & & \\
\hline COPD & 0.66 (0.63 to 0.7$)$ & 2.03 (1.22 to 3.38$)$ & \\
\hline Hemiplegia or paraplegia & 2.25 (1.8 to 2.82$)$ & & \\
\hline Renal disease & 1.11 (1.05 to 1.18$)$ & & \\
\hline Cancer & $1.97(1.82$ to 2.14$)$ & & 1.33 (1.08 to 1.65$)$ \\
\hline Moderate/severe liver disease & 2.07 (1.69 to 2.54$)$ & & 1.61 (1.11 to 2.32$)$ \\
\hline Metastatic cancer & $4.87(4.4$ to 5.4$)$ & & $2.33(1.75$ to 3.1$)$ \\
\hline Axial CT of thorax & 0.64 (0.56 to 0.72$)$ & & \\
\hline Non-invasive mechanical ventilation & 2.15 (1.88 to 2.46$)$ & & \\
\hline Invasive mechanical ventilation & 4.59 (3.94 to 5.34$)$ & & \\
\hline Dialysis & 2.01 (1.68 to 2.4$)$ & 2.09 (1.26 to 3.47$)$ & 1.77 (1.31 to 2.4$)$ \\
\hline Pressure ulcers & 2.5 (2.24 to 2.78$)$ & & 1.65 (1.26 to 2.17$)$ \\
\hline Streptococcus pneumoniae & $0.55(0.49$ to 0.61$)$ & & \\
\hline Haemophilus influenzae & $0.26(0.16$ to 0.41$)$ & & \\
\hline Undergone surgery & & $0.62(0.41$ to 0.96$)$ & $0.73(0.62$ to 0.86$)$ \\
\hline
\end{tabular}

COPD, chronic obstructive pulmonary disease; T2DM, type 2 diabetes mellitus.

Female sex was a risk factor for mortality in patients with T2DM with VAP. Sharpe et al described that the incidence of CAP is lower among women than men, but when women have this disease, they have significantly higher IHM (24\% vs $15 \%$; $=0.009$ ). Differences in the type of CAP could justify this finding. ${ }^{48}$ Similar results have been described by Ali et al, confirming the worse prognosis of female patients with VAP. ${ }^{49}$

Previous surgery was a factor associated with lower mortality in patients with VAP and NV-HAP. We think that patients with T2DM with older age and worse health status are possibly less likely to undergo surgery, which may have resulted in this association.

The strengths of this study included the use of comprehensive, nationwide, population-based register data. We used a case definition for pneumonia hospitalization with increased specificity by using POA as an indicator assigned according to the ICD-10-CM Guidelines.

Several limitations to our investigation must be considered. First, in our investigation we excluded patients under the age of 40 years. The reasons to do this is that according to data from the BDCAP, the SNHS2017 and a report by the Spanish Society of Epidemiology, the prevalence of T2DM becomes significant in adults aged 40 years or older. ${ }^{16} 1750$ Prevalence figures for those below 40 years are under $1 \% .{ }^{16-1850}$ Furthermore, the prevalence of T1DM is higher than T2DM in subjects under 40 years; therefore, the risk of misclassification of a patient as T2DM when he really suffers T1DM is higher for those under 40 years. Finally, this age cut-off point has also been used by previous studies conducted to analyze pneumonia among patients with T2DM. ${ }^{26} 2930$

Second, our data source (RAE-CMBD) is limited by the lack of laboratory or radiology results, treatments, such as information on oxygen or corticoids therapy and clinical characteristics of the pneumonias. Furthermore, we do not have information on duration of ventilatory support, days in the intensive care unit, vaccinations or severity of the respiratory disease.

Third, regarding the characteristics of diabetes, we lack information on disease duration, complications, glycemic control and specific treatment.

Fourth, in most cases of a pneumonia acquired during the hospital admission pathogens are not cultured. This has also been reported in a recent investigation from the USA where of 110 HAP in only $46(42 \%)$ a pathogen was reported. ${ }^{6}$ 
In conclusion, the incidence rates of the three types of pneumonia were higher in patients with T2DM than in patients with non-T2DM. IHM was significantly lower among patients with T2DM with VAP than matched patients without diabetes, and no differences in IHM were found for CAP or NV-HAP.

Higher mortality rates in patients with diabetes with any pneumonia type were associated with increasing age, presence of comorbidity and dialysis. In patients with VAP, the risk of IHM was higher among females.

\section{Author affiliations}

${ }^{1}$ Preventive Medicine and Public Health Teaching and Research Unit, Health Sciences Faculty, Universidad Rey Juan Carlos, Madrid, Spain ${ }^{2}$ Department of Public Health \& Maternal and Child Health, Faculty of Medicine, Universidad Complutense de Madrid, Madrid, Spain ${ }^{3}$ Respiratory Department, Hospital General Universitario Gregorio Marañón, Facultad de Medicina, Universidad Complutense de Madrid, Instituto de Investigación Sanitaria Gregorio Marañón (IISGM), Madrid, Spain ${ }^{4}$ Faculty of Nursing, Physiotherapy and Podology, Universidad Complutense de Madrid, Madrid, Comunidad de Madrid, Spain

Contributors AL-d-A and RJ-G were responsible for the study concept and design, participated in the interpretation of the data and drafted the manuscript. RA-V, JdM-D, ZJ, JJZ-L and ML-H searched the literature, interpreted the results and revised the manuscript. VH-B designed the analyses and performed the bulk of the data analysis. All authors critically revised the manuscript and approved the final version to be published.

Funding Fondo de Investigaciones Sanitarias (FIS)—Health Research Fund, Instituto de Salud Carlos III) cofinanced by the Fondo Europeo de Desarrollo Regional (FEDER, "Una manera de hacer Europa") of the European Union (grant no: $\mathrm{Pl} 16 / 00564)$

\section{Competing interests None declared.}

Patient consent for publication Not required.

Provenance and peer review Not commissioned; externally peer reviewed.

Data availability statement Data are available on reasonable request. The data underlying the results presented in the study are available from the Spanish Ministry of Health (https://www.mscbs.gob.es/estadEstudios/estadisticas/ estadisticas/estMinisterio/SolicitudCMBDdocs/Formulario_Peticion_Datos_CMBD. pdf). The data are owned by the Ministry of Health and authors do not have permission to share the data.

Open access This is an open access article distributed in accordance with the Creative Commons Attribution Non Commercial (CC BY-NC 4.0) license, which permits others to distribute, remix, adapt, build upon this work non-commercially, and license their derivative works on different terms, provided the original work is properly cited, appropriate credit is given, any changes made indicated, and the use is non-commercial. See: http://creativecommons.org/licenses/by-nc/4.0/.

\section{ORCID iDs}

Romana Albaladejo-Vicente http://orcid.org/0000-0003-4710-2912

Zichen Ji http://orcid.org/00-0002-1086-4131

\section{REFERENCES}

1 GBD 2016 Lower Respiratory Infections Collaborators. Estimates of the global, regional, and national morbidity, mortality, and aetiologies of lower respiratory infections in 195 countries, 1990-2016: a systematic analysis for the global burden of disease study 2016. Lancet Infect Dis 2018;18:1191-210.

2 de Miguel-Díez J, Jiménez-García R, Hernández-Barrera V, et al. Trends in hospitalizations for community-acquired pneumonia in Spain: 2004 to 2013. Eur J Intern Med 2017;40:64-71.

3 Ferreira-Coimbra J, Sarda C, Rello J. Burden of community-acquired pneumonia and unmet clinical needs. Adv Ther 2020;37:1302-18.

4 Cillóniz C, Dominedò C, Pericàs JM, et al. Community-Acquired pneumonia in critically ill very old patients: a growing problem. Eur Respir Rev 2020;29:190126.
5 Quan TP, Fawcett NJ, Wrightson JM, et al. Increasing burden of community-acquired pneumonia leading to hospitalisation, 1998-2014. Thorax 2016;71:535-42.

6 Magill SS, O'Leary E, Janelle SJ, et al. Changes in prevalence of health care-associated infections in U.S. hospitals. N Engl J Med 2018;379:1732-44.

7 Righi E, Aggazzotti G, Ferrari E, et al. Trends in ventilatorassociated pneumonia: impact of a ventilator care bundle in an Italian tertiary care hospital intensive care unit. Am J Infect Control 2014:42:1312-6.

8 Khan R, Al-Dorzi HM, Al-Attas K, et al. The impact of implementing multifaceted interventions on the prevention of ventilator-associated pneumonia. Am J Infect Control 2016;44:320-6.

9 Giuliano KK, Baker D, Quinn B. The epidemiology of nonventilator hospital-acquired pneumonia in the United States. Am J Infect Control 2018;46:322-7.

10 McDonald HI, Nitsch D, Millett ERC, et al. New estimates of the burden of acute community-acquired infections among older people with diabetes mellitus: a retrospective cohort study using linked electronic health records. Diabet Med 2014;31:606-14.

11 Kornum JB, Thomsen RW, Riis A, et al. Diabetes, glycemic control, and risk of hospitalization with pneumonia: a population-based case-control study. Diabetes Care 2008;31:1541-5.

12 Shah BR, Hux JE. Quantifying the risk of infectious diseases for people with diabetes. Diabetes Care 2003;26:510-3.

13 Campling J, Jones D, Chalmers JD, et al. The impact of certain underlying comorbidities on the risk of developing hospitalised pneumonia in England. Pneumonia 2019;11:4.

14 Koziel H, Koziel MJ. Pulmonary complications of diabetes mellitus. pneumonia. Infect Dis Clin North Am 1995;9:65-96.

15 Vardakas KZ, Siempos II, Falagas ME. Diabetes mellitus as a risk factor for nosocomial pneumonia and associated mortality. Diabet Med 2007;24:1168-71.

16 Subdirección General de Información Sanitaria. Indicadores clínicos en atención primaria 2016. BDCAP. Madrid: Ministerio de Sanidad, Consumo Y Bienestar social, 2019. Available: https://www.mscbs. gob.es/eu/estadEstudios/estadisticas/estadisticas/estMinisterio/ SIAP/BDCAP_Indic_clinic_Cardiovasc_2016.pdf [Accessed 9 May 2020].

17 Instituto Nacional de Estadística. Encuesta Nacional de Salud 2017 [Spanish National Health Survey 2017]. Available: www.mscbs.gob. es/estadEstudios/estadisticas/ encuestaNacional/encuesta2017.htm [Accessed 9 May 2020].

18 Soriguer F, Goday A, Bosch-Comas A, et al. Prevalence of diabetes mellitus and impaired glucose regulation in Spain: the Di@bet.es Study. Diabetologia 2012;55:88-93.

19 Ministerio de Sanidad, Consumo Y Bienestar social. Registro de Actividad de Atención Especializada. RAE-CMBD. Available: www.mscbs.gob.es/estadEstudios/estadisticas/cmbdhome.htm [Accessed 7 Mar 2020].

20 Charlson ME, Pompei P, Ales KL, et al. A new method of classifying prognostic comorbidity in longitudinal studies: development and validation. J Chronic Dis 1987;40:373-83.

21 Quan H, Sundararajan V, Halfon P, et al. Coding algorithms for defining comorbidities in ICD-9-CM and ICD-10 administrative data. Med Care 2005;43:1130-9.

22 Austin PC. An introduction to propensity score methods for reducing the effects of confounding in observational studies. Multivariate Behav Res 2011;46:399-424.

23 D'Agostino RB. Propensity score methods for bias reduction in the comparison of a treatment to a non-randomized control group. Stat Med 1998:17:2265-81.

24 Instituto Nacional de Estadística: national Stadistical Institute. population estimates, 2016. Available: www.ine.es [Accessed 8 Jan 2020].

25 Austin PC. Comparing paired vs non-paired statistical methods of analyses when making inferences about absolute risk reductions in propensity-score matched samples. Stat Med 2011;30:n/a-301.

26 López-de-Andrés A, de Miguel-Díez J, Jiménez-Trujillo I, et al. Hospitalisation with community-acquired pneumonia among patients with type 2 diabetes: an observational population-based study in Spain from 2004 to 2013. BMJ Open 2017;7:e013097.

27 Hamilton EJ, Martin N, Makepeace A, et al. Incidence and predictors of hospitalization for bacterial infection in community-based patients with type 2 diabetes: the Fremantle diabetes study. PLoS One 2013;8:e60502.

28 Jackson ML, Neuzil KM, Thompson WW, et al. The burden of community-acquired pneumonia in seniors: results of a populationbased study. Clin Infect Dis 2004;39:1642-50.

29 López-de-Andrés A, Perez-Farinos N, de Miguel-Díez J, et al. Type 2 diabetes and postoperative pneumonia: an observational, 
population-based study using the Spanish hospital discharge database, 2001-2015. PLoS One 2019;14:e0211230.

30 Jiménez-Trujillo I, Jiménez-García R, de Miguel-Díez J, et al. Incidence, characteristic and outcomes of ventilator-associated pneumonia among type 2 diabetes patients: an observational population-based study in Spain. Eur J Intern Med 2017;40:72-8.

31 Karatas M, Saylan S, Kostakoglu U, et al. An assessment of ventilator-associated pneumonias and risk factors identified in the intensive care unit. Pak J Med Sci 2016;32:817-22.

32 Rady MY, Johnson DJ, Patel BM, et al. Influence of individual characteristics on outcome of glycemic control in intensive care unit patients with or without diabetes mellitus. Mayo Clin Proc 2005;80:1558-67.

33 Baker D, Quinn B. Hospital acquired pneumonia prevention Initiative-2: incidence of nonventilator hospital-acquired pneumonia in the United States. Am J Infect Control 2018;46:2-7.

34 Sopena N, Heras E, Casas I, et al. Risk factors for hospital-acquired pneumonia outside the intensive care unit: a case-control study. Am $J$ Infect Control 2014;42:38-42.

35 de Miguel-Díez J, Jiménez-García R, Hernández-Barrera V, et al. Ventilatory support use in hospitalized patients with communityacquired pneumonia. Fifteen-year trends in Spain (2001-2015). Archivos de Bronconeumología 2020.

36 Sibbel S, Sato R, Hunt A, et al. The clinical and economic burden of pneumonia in patients enrolled in Medicare receiving dialysis: a retrospective, observational cohort study. BMC Nephrol 2016;17:199

37 Huijts SM, van Werkhoven CH, Bolkenbaas M, et al. Post-hoc analysis of a randomized controlled trial: diabetes mellitus modifies the efficacy of the 13-valent pneumococcal conjugate vaccine in elderly. Vaccine 2017:35:4444-9.

38 Yin JK, Jayasinghe SH, Charles PG, et al. Determining the contribution of $<$ em $>$ Streptococcus pneumoniae $</$ em $>$ to community-acquired pneumonia in Australia. Med J Aust 2017;207:396-400.

39 Ministry of health, social services and equality. vaccination against pneumococcal infections in risk groups. Available: www.msssi.gob. es/profesionales/saludPublica/prevPromocion/vacunaciones/docs/ Neumococo_Gruposriesgo.pdf [Accessed 3 Mar 2020].
40 Tumbarello M, De Pascale G, Trecarichi EM, et al. Clinical outcomes of Pseudomonas aeruginosa pneumonia in intensive care unit patients. Intensive Care Med 2013;39:682-92.

41 Kollef MH, Chastre J, Fagon J-Y, et al. Global prospective epidemiologic and surveillance study of ventilator-associated pneumonia due to Pseudomonas aeruginosa. Crit Care Med 2014;42:2178-87.

42 López-Cuadrado T, Llácer A, Palmera-Suárez R, et al. Trends in infectious disease mortality rates, Spain, 1980-2011. Emerg Infect Dis 2014;20:782-9.

43 Kaplan V, Angus DC, Griffin MF, et al. Hospitalized communityacquired pneumonia in the elderly: age- and sex-related patterns of care and outcome in the United States. Am J Respir Crit Care Med 2002;165:766-72.

44 McAlister FA, Majumdar SR, Blitz S, et al. The relation between hyperglycemia and outcomes in 2,471 patients admitted to the hospital with community-acquired pneumonia. Diabetes Care 2005;28:810-5.

45 Nie W, Zhang Y, Jee SH, et al. Obesity survival paradox in pneumonia: a meta-analysis. BMC Med 2014;12:61.

46 Loeb M. Epidemiology of community- and nursing homeacquired pneumonia in older adults. Expert Rev Anti Infect Ther 2005;3:263-70 https://doi.org/

47 Bauer K, Rock K, Nazzal M, et al. Pressure ulcers in the United States' inpatient population from 2008 to 2012: results of a retrospective nationwide study. Ostomy Wound Manage 2016;62:30-8.

48 Sharpe JP, Magnotti LJ, Weinberg JA, et al. Gender disparity in ventilator-associated pneumonia following trauma: identifying risk factors for mortality. J Trauma Acute Care Surg 2014;77:161-5.

49 Ali HS, Khan FY, George S, et al. Epidemiology and outcome of ventilator-associated pneumonia in a heterogeneous ICU population in Qatar. Biomed Res Int 2016;2016:1-8.

50 Sociedad Española de Epidemiología. Diabetes mellitus tipo 2:impacto en la salud pública y estrategias de prevención. Available: https://www.seepidemiologia.es/documents/dummy/Monograf\% C3\%ADa\%20SEE.pdf [Accessed 12 May 2020]. 


\section{Correction: Incidence and outcomes of hospitalization for community- acquired, Ventilator-associated and non-ventilator Hospital-acquired pneumonias in patients with type 2 diabetes mellitus in Spain}

Lopez-de-Andres A, Albadalejo-Vicente R, de Miguel-Diez J, et al. Incidence and outcomes of hospitalization for community-acquired, ventilator-associated and nonventilator hospital-acquired pneumonias in patients with type 2 diabetes mellitus in Spain. BMJOpen Diabetes Res Care 2020;8:e001447. doi: 10.1136/bmjdrc-2020-001447.

This article was previously published with an error.

The surname of Romana Albadalejo-Vicente was spelt incorrectly. The correct name is Romana Albaladejo-Vicente.

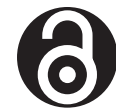

\section{OPEN ACCESS}

Open access This is an open access article distributed in accordance with the Creative Commons Attribution Non Commercial (CC BY-NC 4.0) license, which permits others to distribute, remix, adapt, build upon this work noncommercially, and license their derivative works on different terms, provided the original work is properly cited, appropriate credit is given, any changes made indicated, and the use is non-commercial. See: http://creativecommons. org/licenses/by-nc/4.0/.

(C) Author(s) (or their employer(s)) 2020. Re-use permitted under CC BY-NC. No commercial re-use. See rights and permissions. Published by BMJ.

BMJ Open Diab Res Care 2020;8:e001447corr1. doi:10.1136/bmjdrc-2020-001447corr1

(A) Check for updates 